\title{
The benefits of Square dancing as a means of physical activity for Czech dancers with hearing loss
}

\author{
Petra Kurková* and Jessica J. Maertin \\ Faculty of Physical Culture, Palacký University, Olomouc, Czech Republic
}

Copyright: (c) 2014 P. Kurková and J. J. Maertin. This is an open access article licensed under the Creative Commons Attribution License (http://creativecommons.org/licenses/by/4.0/).

\begin{abstract}
Background: Hearing, a strong line of communication that enables individuals to learn about the world around them, is a major factor contributing to the psychomotor development of every individual. Hearing loss can also affect the conception and perception of sounds and rhythm. Objective: The purpose of this study was to describe and analyse the benefits of Square and Round dancing for persons with hearing loss. Methods: The present study is an analyticdescriptive qualitative research. The sample was constituted non-probabilistically based on the following features: a) a participant had to have hearing problems (hearing loss) and b) had to have participated regularly in Square dance for at least two years. Each participant was asked to name possible people to be interviewed (snowball technique). We analysed the data of 7 individuals ( 6 males and 1 female) with hearing loss. The mean age of the dancers with hearing loss was 51.3 years. The participants had no cochlear implants or any other physical or vision related impairments. Results: The present findings constitute the first published survey regarding Czech Square dancers' status, their family's hearing status, hearing aid use, communication preference, education in integrated or segregated settings, the influence of family background on dance initiation, coach preference (hearing or deaf), and the environment for participation in Square dance as a mode of physical activity with regular dancers and with dancers with hearing loss as well. In the present sample of dancers with hearing loss, most were from hearing families and had hearing siblings. The degree to which individuals with hearing loss feel comfortable with the hearing world appears to influence their later preference for participating in regular, as opposed to segregated, physical activities. More than half of the dancers with hearing loss who participated in this research study would like to meet with the deaf minority. One of the main reasons for this is to get to know new people and to share experiences with those who have the same problems with hearing. Conclusion: The present study emphasizes the need for the additional support and promotion of the accessibility to their chosen physical activities for individuals with hearing loss. This will be best accomplished if both the deaf and hearing communities work together.
\end{abstract}

Keywords: communication, motivation, health, community setting

\section{Introduction}

Hearing is one of the most important human senses. It plays a significant role not only in interpersonal communication, but it also provides acoustic information from one's surroundings, including the localization of sounds that may signal potential dangers or threats. And thanks to hearing, we can also perceive emotions.

Individuals with hearing loss may be disadvantaged in terms of health and participation in beneficial physical activities compared to the majority of society due to their information deficit and limited auditory

\footnotetext{
* Address for correspondence: Petra Kurková, Department of Adapted Physical Activities, Faculty of Physical Culture, Palacký University, tř. Míru 115, 77111 Olomouc, Czech Republic. E-mail: kurkova.p@centrum.cz
}

perception (Iezzoni, O’Day, Killen, \& Harker, 2004; Pollard \& Barnett, 2009; Soto-Rey, Pére-Tejero, RojoGonzález, \& Reina, 2014). The main factors impeding their engagement in leisure activities include a feeling of indifference and uncertainty from the majority of society, as well as a lack of available information (Tsai \& Fung, 2005).

Although hearing loss is not considered to be a developmental disability, it can affect communication, including speech and language, intelligence, social and emotional development, academic achievement and also motor performance (Auxter, Pyfer, \& Huettig, 1997; Darrow, 1984; Kosel \& Froböse, 1999; Marschark, 2007; Scheetz, 2012).

Dance is a locomotive activity that has positive physical, mental, and emotional benefits for its 
participants. There are many known benefits from dancing, including artistic, educational, and therapeutic (Daley \& Buchanan, 1999; Dinold, 2014; Hunter, 2013; Reber \& Sherrill, 1981).

The importance of dance as a suitable means of physical activity that includes social and health effects grows significantly for those individuals with disabilities who have a lower level of habitual activity (Kosma, Cardinal, \& Rintala, 2002; Longmuir \& Bar-Or, 2000). There have been several studies published about the possible influence of dance and creative movement on personal development for individuals with and without disabilities. Dinold (2000) identified those important factors: the significance of movement when used as a media of creative expression, the importance of the coherence of perception and movement, the development of personal identity; and the impact of space and time in dance on an individual's development of orientation in space and time.

Whereas the choreography of ballroom dance is predetermined, Square and Round dances are unique because the dancers do not know the choreography beforehand. They only know some moves that make up the dance. Square and Round dances are danced following simple English cues. The actual dance is then created at the given moment by a caller/cuer who gives clues to the dancers within the context of the rhythm, telling them which moves to perform. The names of the moves have been standardized in English and are thus performed according to the same English cues both in the Czech Republic as well as in all other countries around the world.

For the purpose of this study, Square dance is defined as a non-elite type of dance for recreational, community or educational purposes, excluding dance programmes with a high level of intensity and frequency of training. This type of dance includes programmes in school, after school or in a community setting.

The purpose of this study was to describe and analyse the benefits of Square and Round dancing for persons with hearing loss. Up to now, there has been no research on individuals with hearing loss related to Square dancing as a mode of physical activity.

\section{Method}

\section{Participants}

The participants in the study were 7 dancers ( 6 male and 1 female) with hearing loss. The mean age of the dancers with hearing loss was 51.3 years. Not counting one participant with hearing loss who reported having problems with balance, the participants had no cochlear implants or any other physical or vision related impairments.

The sampling of dancers with hearing loss was constituted non-probabilistically from the following features: a) a participant had to have hearing loss and b) they must have participated regularly in Square dance for at least two years.

\section{Data collection}

The data were gathered through semi-structured interviews designed by both authors. Each participant was asked to name possible people to be interviewed (the snowball technique). Dancers with hearing loss were asked about their family backgrounds for a possible history of hearing impairment, their school education to identify integration or segregation, their hearing loss, and their overall history of involvement with Square dance. The selection of interview questions was based on a study by Kurková, Válková, and Scheetz (2011). Each interview was held in a quiet environment with no interruptions. The length of each interview was approximately 45 minutes. Each dancer with hearing loss was informed of the purpose of the interview and asked if they would participate in the study. Upon consent, the participant or their legal representative was enrolled in the study, as approved by the Ethics Committee of the Faculty of Physical Culture, Palacký University Olomouc and the interview began.

\section{Data analysis}

Data were recorded and transcribed verbatim by the one of the authors (J. M.). Subsequently, data obtained from the questioning were compared, named, and put into categories (in the case of open questions) based on methods used by Strauss and Corbin (1998). The data were described in relative and absolute frequencies and according to the following criteria: demographic and family hearing status, communication preferences and technical support, education of the dancers with hearing loss and dance participation.

\section{Results}

\section{Family hearing status and education of the dancers}

All participants in the study mentioned that their parents as well as siblings had no hearing impairment (Table 1). Of the dancers who suffered from hearing loss, only one did so from birth (Table 1). The aetiology of the hearing loss of the dancers was based on the consequences of acoustic traumas, head injuries, chemotherapy or retracted eardrums.

Regarding educational background, all the dancers with hearing loss were educated in regular schools and 
Table 1

Family hearing status demographic

\begin{tabular}{|c|c|c|c|c|c|c|c|}
\hline & \multicolumn{7}{|c|}{ Participant } \\
\hline & D1 & D2 & D3 & D4 & D5 & D6 & D7 \\
\hline \multicolumn{8}{|l|}{ Gender } \\
\hline Female & - & - & - & - & - & + & - \\
\hline Male & + & + & + & + & + & - & + \\
\hline \multicolumn{8}{|l|}{ Onset of hearing loss } \\
\hline Year of age & 41 & 49 & 44 & 44 & 55 & 18 & FB \\
\hline \multicolumn{8}{|l|}{ Hearing loss in percentage } \\
\hline Left/right & $45 / 45$ & $81 / 23$ & $2 / 78$ & $15 / 30$ & $34 / 35$ & $14 / 3$ & $42 / 42$ \\
\hline \multicolumn{8}{|l|}{ Reason of hearing loss } \\
\hline Acoustic trauma & - & - & - & + & + & - & - \\
\hline Head and back injuries & - & - & - & - & - & + & - \\
\hline Chemotherapy & + & - & - & - & - & - & - \\
\hline Inverted eardrum & - & - & - & - & - & - & + \\
\hline Sudden declination & - & - & + & - & - & - & - \\
\hline Unknown & - & + & - & - & - & - & - \\
\hline \multicolumn{8}{|l|}{ Hearing state of parents } \\
\hline Both parents hearing & + & + & + & + & + & + & + \\
\hline \multicolumn{8}{|l|}{ Hearing state of siblings } \\
\hline Hearing sibling & + & - & + & + & + & + & + \\
\hline No sibling & - & + & - & - & - & - & - \\
\hline \multicolumn{8}{|l|}{ Education } \\
\hline In regular schools & + & + & + & + & + & + & + \\
\hline Leaving examination & + & + & + & + & - & + & $\mathrm{s}$ \\
\hline University degree & - & + & + & - & - & + & - \\
\hline \multicolumn{8}{|l|}{ Occupation } \\
\hline ICT & - & - & + & - & - & - & - \\
\hline Pensioner & + & + & - & - & + & - & - \\
\hline Pupil & - & - & - & - & - & - & + \\
\hline Teacher & - & - & - & - & - & + & - \\
\hline
\end{tabular}

Note. $\mathrm{FB}=$ from birth, $\mathrm{s}=$ student.

one of them was still a student. Five dancers with hearing loss had passed their leaving examination and three of them replied that they had graduated from university. The research sample of dancers with hearing loss included pensioners, an IT specialist, a teacher and a pupil (Table 1).

\section{Hearing aid and communication}

Despite the fact that dancers with hearing loss had slight to profound hearing impairment, only one of them used a hearing aid (Table 2). This one hearing aid user reported that the hearing aid helped him to communicate more easily. The dancers' primary mode of communication was mostly spoken speech supported by lip reading or written text (Table 2). Only three of the dancers with hearing loss mentioned that they do not have difficulties communicating. Others stated that the hearing population is uninformed or indifferent.

During everyday communication in a calm atmosphere, the dancers had no trouble understanding spoken words or they eliminated their problems beforehand, i.e., by choosing a specific place at the discussion table. Most of the dancers with hearing loss agreed that they have trouble communicating in a noisy environment and amongst crowds, for instance, in a pub. Due to their hearing loss, they were not able to filter out the noise, and therefore, they could hear a person talking, but could not understand them. Such impaired ability to localize a sound in a noisy environment is also reflected in Square dance and Round dance: “... because it is important there to catch the instruction that comes from the caller or cuer, and you have the 
Table 2

Communication and hearing aid

\begin{tabular}{|c|c|c|c|c|c|c|c|}
\hline & \multicolumn{7}{|c|}{ Participant } \\
\hline & D1 & D2 & D3 & D4 & D5 & D6 & D7 \\
\hline \multicolumn{8}{|l|}{ Use of hearing aid } \\
\hline Yes & - & - & - & - & - & - & + \\
\hline No & + & + & + & + & + & + & - \\
\hline \multicolumn{8}{|c|}{ Primary mode of communication } \\
\hline Spoken speech & + & + & + & + & + & + & + \\
\hline Lip reading & - & - & + & - & - & - & + \\
\hline Written text & - & - & - & + & - & + & + \\
\hline \multicolumn{8}{|c|}{ Difficulties in communicating } \\
\hline I have no problem & - & - & + & - & + & + & - \\
\hline Uninformed & + & + & - & + & - & - & + \\
\hline Indifferent & - & - & - & + & - & - & - \\
\hline
\end{tabular}

music playing in the background. This is the greatest problem because I need to understand...The music that helps keep the dance rhythm is a kind of humming for me in the background that prevents me from understanding the instructions" (D3, 55 years old).

"It [hearing loss] does not hinder me much in my personal life. I explained to my daughter and my close relatives that I simply have weak hearing and so I occasionally have to ask repeatedly what they have said. So it does not bother me much. But the trouble began when I started dancing, because some (co-)dancers made it clear to me, through non-verbal communication, that I was not catching the rhythm. As there are now more of us with some form of hearing impairment (a friend of mine even has a hearing aid), we naturally learnt to locate ourselves within the square as close to the caller as possible" (D6, 48 years old).

To put this in context, audiologists categorize hearing based on pure-tone frequencies ranging from 500 to $4000 \mathrm{~Hz}$ : no hearing loss $0-25 \mathrm{~dB}$, no or very slight hearing problems, able to hear whispers; slight hearing loss 26-40 dB, able to hear and repeat words spoken in a normal tone of voice at 1 metre; moderate hearing loss 41-60 dB, able to hear and repeat words spoken with a raised voice at 1 metre; severe hearing loss $61-80 \mathrm{~dB}$, able to hear some words when shouted into the better ear; and profound hearing loss including deafness of $81 \mathrm{~dB}$ or greater, unable to hear and understand even a shouting voice (World Health Organization, 2014).

Dancers with hearing loss try to solve their disadvantage with explanations to prevent misunderstandings. One of the dancers with hearing loss summed it up as follows (translated by the authors into English with the assistance of an English native speaker; attention was given to maintaining the original intent of the interviewee rather than creating perfect English sentences): "The fact that I suffer from a hearing impairment truly is a handicap for me, not only in dance, but also generally in my life and I simply try to solve it by explaining it to people. Hey, look, I have a hearing disorder. Don't be mad if I do not respond" (D3, 55 years old).

\section{Dance participation}

Regarding parental participation in dance, only 2 dancers with hearing loss stated that both parents danced. In three cases, the dancers with hearing loss reported that their parents encouraged them to participate in dance. The majority of the dancers with hearing loss had a hearing coach and six of them preferred a hearing coach. According to the findings (Table 3), three of the dancers with hearing loss stated that they would want to dance with deaf dancers. The reasons for this answer are that they have the same problems with hearing and they enjoy the same hobby and also to understand their world and culture. Those who stated that they do not want to dance with deaf dancers stated that they are hard of hearing rather than deaf or that they do not use sign language.

All dancers with hearing loss except for one stated that they would recommend dancing to other people who have hearing loss (Table 3). They argued: "It is a perfect form of relaxation where with some effort you can overcome your problems with deafness... I can learn something new and I can fight my handicap" (D2, 64 years old). Another participant stated: "It is a form of active group entertainment where all dancers must cooperate in a square. It strengthens the feeling of togetherness of a handicapped person with others as handicapped persons are often partially or totally 
Table 3

Initiation into dance and dance participation

\begin{tabular}{|c|c|c|c|c|c|c|c|}
\hline & \multicolumn{7}{|c|}{ Participant } \\
\hline & D1 & D2 & D3 & D4 & D5 & D6 & D7 \\
\hline \multicolumn{8}{|l|}{ Parents' participation in dance } \\
\hline Both parents practiced a dance & - & + & + & - & - & - & - \\
\hline Both parents did not practiced a dance & + & - & - & + & + & + & + \\
\hline \multicolumn{8}{|l|}{ Onset in square dancing } \\
\hline Year of age & 45 & 40 & 16 & 50 & 59 & 17 & 6 \\
\hline \multicolumn{8}{|l|}{ Initiation in square dance } \\
\hline Friends & + & + & - & - & + & - & - \\
\hline Employee & - & - & - & + & - & - & - \\
\hline Parents & - & - & + & + & - & - & + \\
\hline Teachers/students & - & - & - & - & - & + & + \\
\hline Myself & - & - & + & - & - & - & - \\
\hline \multicolumn{8}{|l|}{ Do you have a coach? } \\
\hline Yes & - & + & - & - & + & + & + \\
\hline No & + & - & + & + & - & - & - \\
\hline \multicolumn{8}{|l|}{ Preference of coaches } \\
\hline Hearing coach & - & + & + & + & + & + & + \\
\hline Deaf coach & - & - & - & - & - & - & - \\
\hline It is not important & + & - & - & - & - & - & - \\
\hline \multicolumn{8}{|l|}{ Do you want to dance with deaf dancers? } \\
\hline Yes & - & - & + & + & - & + & - \\
\hline No & - & + & - & - & - & - & + \\
\hline It is not important & + & - & - & - & + & - & - \\
\hline \multicolumn{8}{|l|}{ What is your reason for this? } \\
\hline $\begin{array}{l}\text { The same problems with hearing and } \\
\text { the same hobby }\end{array}$ & - & - & + & + & - & - & - \\
\hline $\begin{array}{l}\text { To understand the deaf world/deaf } \\
\text { culture }\end{array}$ & - & - & - & - & - & + & - \\
\hline I do not know sign language & - & + & - & - & - & - & + \\
\hline I am hard of hearing & - & + & - & - & - & - & - \\
\hline \multicolumn{8}{|l|}{$\begin{array}{l}\text { Do you have difficulties sensing sound } \\
\text { during dancing? }\end{array}$} \\
\hline Yes & + & + & + & + & + & + & - \\
\hline \multicolumn{8}{|l|}{ If yes, specify this } \\
\hline Balance problems & - & - & + & - & - & - & - \\
\hline Understanding the cuer & + & + & + & + & + & + & - \\
\hline $\begin{array}{l}\text { I cannot hear the instructions from } \\
\text { co-dancers }\end{array}$ & + & + & - & + & - & + & - \\
\hline $\begin{array}{l}\text { I must always assume the same posi- } \\
\text { tion so that my better ear is pointed } \\
\text { towards the source of music/caller. }\end{array}$ & - & + & + & - & - & + & - \\
\hline $\begin{array}{l}\text { Other dancers are angry with me that I } \\
\text { make mistakes. }\end{array}$ & + & - & - & - & - & + & - \\
\hline \multicolumn{8}{|l|}{$\begin{array}{l}\text { Would you recommend square dancing to } \\
\text { other people who have hearing loss? }\end{array}$} \\
\hline Yes & + & + & + & + & + & + & + \\
\hline No & - & - & - & - & - & - & - \\
\hline
\end{tabular}


excluded from the community. However, in the case of Square dancing, a high level of mutual tolerance is a prerequisite. Couple dancing or Round dances require only a certain understanding with your partner, and therefore I always chosen those partners about whom I knew they would tolerate my handicap" (D3, 55 years old).

Another dancer with hearing loss said: "There is a nice bunch of people in the Square dance group, and they help when it is necessary. The body and mind work hard if needed" (D4, 69 years old). As a reason for giving a negative answer, one dancer with hearing loss stated: "It is quite unpleasant if they (the dancers) have bigger problems with hearing because they can seriously spoil the whole experience for others" (D5, 62 years old).

In a question as to whether the dancers with hearing loss have trouble with perceiving the sounds and rhythm of the Square dance, only one dancer (the one with the hearing aid) replied that he had no problems with perceiving the sounds and the rhythm when Square dancing. However, he mentioned the fact that dancers must fully concentrate during the dance. Other dancers with hearing loss stated they had trouble understanding the instructions, failed to hear the instructions from their co-dancers, and therefore they kept choosing the same position in the Square dance so that they could point their better ear towards the source of music and the caller.

One of the dancers described his troubles as follows: "Well, with regards to Square dancing, after all these years I really do not have any trouble, because if, for instance, I mishear the instruction due to the music, I can use my experience or the movements of other dancers to quickly figure out what move will follow. It is a bit harder with Round dancing because I dance with a partner. And if I do the Round dance with someone other than with my wife, I have problems because I respond incorrectly. But I mostly dance with my wife and we are already quite well coordinated" (D2, 64 years old).

In Square dancing, dancers with hearing loss try to "copy" the movements of other dancers or try to estimate the next moves based on their experience. A dancer with hearing loss compared this kind of deductive thinking to a Lego building set: "Basically, it is a Lego where I have a bunch of bricks, and I can use them to build virtually anything, an endless number of things, but I cannot combine them arbitrarily, that's impossible" (D3, 55 years old).

This technique, however, cannot be used with Round dance. Therefore, some dancers with hearing loss inform others of their disadvantage beforehand and apologize for potential mistakes: "It happens from time to time. Before we start dancing I simply inform the others of my situation, and if I am wrong, then please excuse me. But the girls here are mostly cool and easy-going (a laugh)... I may not always know how to lead her or what move follows. So sometimes my partner needs to cooperate, and it is up to me to tell my partner, look, I can't hear well, so let's act accordingly" (D2, 64 years old).

Dancers with hearing loss also mentioned that they overcome all obstacles caused by their hearing impairment using great concentration, imitating the movements of other dancers in the square when they mishear the instructions or by taking the most suitable place and position in the dance hall and lip-reading. When they mishear the instructions in a Round dance, they let their partner lead the dance. Coordination and teamwork between the dancing pair as well as the ability to keep your dancing posture is, however, a prerequisite. Or they inform the caller/cuer that the music is too loud and it is preventing them from catching the instructions. Such obstacles are, nevertheless, compensated for by the positive changes dancing makes in their lives. They all agreed that dancing provides mental and internal stress release, satisfaction and happiness.

One of the dancers with hearing loss described the benefits as follows: "For me, Square dancing is a huge source of mental support, the bunch of people here, the life style. It is a cure for my stress... My wife and I also go to couple dance classes. However, there is nobody to tell us what to do next, there is just the music. It is completely different there... I am already retired, but when I used to work, I was very stressed at work and so when we went out once a week to dance a country dance, I actually felt the stress washing out of me" (D2, 64 years old). Another dancer with hearing loss puts it differently: "[Dancing] offers active relaxation and enjoyment, and namely Square dancing and Round dancing bring many long-term friendships. It helps me unwind from the stress at work. Square dancing and my friends from the Square dance classes have helped me quite a few times to overcome crises in my life" (D3, 55 years old).

\section{Discussion}

The aim of this study was to describe and analyse the benefits of dancing for persons with hearing loss. Up to now, there has been no research on individuals with hearing loss related to Square dancing as a mode of physical activity. The present findings are the first published survey on the status of Czech Square dancers, their family's hearing status, hearing aid use and communication preference, education in integrated 
or segregated settings, family background for dance initiation, coach preference (hearing or deaf), and an environment for using Square dancing as a mode of physical activity with regular dancers or dancers with hearing loss.

In the present sample of dancers with hearing loss, most were from hearing families and had hearing siblings. This finding is similar to the Gallaudet Research Institute's (2011) report, which indicated that 79.4\% of deaf children are born to hearing parents. The individuals with hearing loss who are comfortable with the hearing world appear to have a greater preference for participating in regular or segregated physical activities.

All participants with hearing loss preferred spoken speech. The means of communication for dancers with hearing loss can influence their socialisation. Similar findings were published by Middleton, Niruban, Girling, and Myint (2010), where 70\% of the participants with hearing loss used speech within their everyday lives.

More than half of the dancers with hearing loss who participated in this research study would like to meet with a deaf person. One of the main reasons for this was so that they could get to know new people and share experiences which those who have the same problems with their hearing. These findings are in accordance with previous studies focused on dance or physical activity (Dinold, 2000; Stewart, Robinson, \& McCarthy, 1991). Nevertheless, it is notable that in a previous study of Kurková, Válková, and Scheetz (2011) different findings were discovered in deaf athletes who frequently described their interactions during sport activities with hearing athletes as being marginalized from socialisation.

Dancers with hearing loss agreed that they benefit from mental and internal relaxation and that they derive delight and satisfaction from physical activity. This activity offers active relaxation and enjoyment to dancers with hearing loss, and, in addition, it brings new long-term friendships into their lives and helps the individuals to take their minds off the hectic course of life. It also helps them to overcome critical periods in their lives.

The findings of this study are in accordance with Dinold (2014) and state that dancing has a positive influence on all participants with hearing loss with respect to relationships and getting in touch with other people. This finding reaffirmed previous research (Kisvetrová, Kurková, Švejdíková, \& Popelková, 2013; Solheim, Kvaerner, Sandvik, \& Falkenberg, 2012) in which it is stated that compensating for hearing loss with a hearing aid can have a positive influence in understanding other people.

\section{Conclusion}

In the present study, dancers with hearing loss were interviewed so that they could describe their participation in Square dancing. Using Square dancing as a means of physical activity for persons with hearing loss means, above all, a methodical-didactical challenge. The lack of perception of important information from their surroundings that such persons experience due to their hearing disorders affects much more their personality structure. External stimuli may acquire different meanings, and the world surrounding persons with hearing loss is perceived and experienced differently than by persons who do not have this impairment.

In order to report on the personally beneficial factors of participating in Square dancing, two main points have to be emphasized: dancers with hearing loss develop a higher level of self-confidence, self-consciousness, openness and autonomy. They emphasized the enhancement of their experience and quality of life by coming to know new people and having fun meeting them, eventually building up long-term relationships.

Recommendations for future research should further investigate the interrelationship between hearing status and dancing by examining and comparing the impact of dancing on dancers with hearing loss, culturally deaf dancers and dancers without hearing loss. The present study emphasizes the need for additional support of access to Square dancing for individuals who have hearing loss and especially for support to deal with their special needs. This will best be accomplished if both the deaf and hearing communities work together.

\section{Acknowledgment}

This work was supported by the ECOP project "Increasing professional competencies of students in healthcare and sports study programmes in relation to persons with a disability" (No. CZ.1.07/2.2.00/28.0181).

\section{References}

Auxter, D., Pyfer, J., \& Huettig, C. (1997). Principles and methods of adapted physical education and recreation. Saint Louis, MO: Mosby Year Book.

Daley, A. J., \& Buchanan, J. (1999). Aerobic dance and physical self-perceptions in female adolescents: Some implications for physical education. Research Quarterly for Exercise and Sport, 70, 196-200.

Darrow, A. A. (1984). A comparison of rhythmic responsiveness in normal and hearing impaired children and investigation of the rhythmic responsiveness to the supra 
segmental aspects of speech perception. Journal of Music Therapy, 21, 48-66.

Dinold, M. (2000). Tanz und kreative Bewegung als lebenslange Entwicklungsförderung für Menschen mit und ohne Behinderung. Ein Beitrag zur Integrationsforschung in der Bewegungs und Sportpädagogik - Entwicklungsförderung zwischen Pädagogik und Therapie [Dancing and creative movement as a long life process for persons with and without disability. Contribution to integration research in movement and sport pedagogy - developments in pedagogy and therapy] (Doctoral dissertation). University of Vienna, Institute for Sports Sciences, Vienna.

Dinold, M. (2014). The impact of the dance and creative activities on the quality of life of individuals with disabilities. In D. Milanović \& G. Sporiš (Eds.), $7^{\text {th }}$ International Scientific Conference on Kinesiology (pp. 22-26). Zagreb, Croatia: University of Zagreb.

Gallaudet Research Institute. (2011). Regional and national summary report of data from the 2009-2010. Annual survey of deaf and hard of hearing children and youth. Washington, DC: GRI, Gallaudet University.

Hunter, A. (2013). Why I dance. Dance Magazine, 87, 72-72. Iezzoni, L. I., O’Day, B. L., Killen, M., \& Harker, H. (2004). Communicating about health care: Observations from persons who are deaf or hard of hearing. Annals of Internal Medicine, 140, 356-362.

Kisvetrová, H., Kurková, P., Švejdíková, B., \& Popelková, R. (2013). Použivání sluchadla jako aspekt kvality života seniorské populace [Usage of hearing aid as an aspect of the quality of life in the senior population]. In F. Murgaš (Ed.), Mezinárodní konference Kvalita života 2013 (pp. 53-62). Liberec: Technical University.

Kosel, H., \& Froböse, I. (1999). Rehabilitation-und Behindertensport: Körper-und Sinnbehinderte [Rehabilitation and disability sport: Body and sensory disability] (2nd ed.). München: Pflaum.

Kosma, M., Cardinal, B. J., \& Rintala, P. (2002). Motivating individuals with disabilities to be physically active. Quest, 54, 116-132.

Kurková, P., Válková, H., \& Scheetz, N. (2011). Factors impacting participation of European elite deaf athletes in sport. Journal of Sports Sciences, 29, 607-618.
Longmuir, P. E., \& Bar-Or, O. (2000). Factors influencing the physical activity levels of youths with physical and sensory disabilities. Adapted Physical Activity Quarterly, 17, 40-53.

Marschark, M. (2007). Raising and educating a deaf child: A comprehensive guide to choices, controversies, and decisions faced by parents and educators (2nd ed.). New York, NY: Oxford University Press.

Middleton, A., Niruban, A., Girling, G., \& Myint, P. K. (2010). Communicating in healthcare setting with people who have hearing loss. BMJ, 341, 726-729.

Pollard, R. Q., \& Barnett, S. (2009). Health-related vocabulary knowledge among deaf adults. Rehabilitation Psychology, 54, 182-185.

Reber, R., \& Sherrill, C. (1981). Creative thinking and dance/ movement skills of hearing impaired youth: An experiment study. American Annals of the Deaf, 126, 1004-1009.

Scheetz, N. A. (2012). Deaf education in the $21^{\text {st }}$ century. Topics and trends. Boston, MA: Pearson.

Solheim, J., Kvaerner, K. J., Sandvik, L., \& Falkenberg, E. S. (2012). Factors affecting older adults' hearing-aid use. Scandinavian Journal of Disability Research, 14, 300-312.

Soto-Rey, J., Pérez-Tejero, J., Rojo-González, J. J., \& Reina, R. (2014). Study od reaction time to visual sitmuli in athletes with and without a hearing impairment. Perceptual and Motor Skills, 119, 123-132.

Stewart, D. A., Robinson, J. A., \& McCarthy, D. (1991). Participation in deaf sport: Characteristics of elite deaf athletes. Adapted Physical Activity Quarterly, 8, 136-145.

Strauss, A., \& Corbin, J. (1998). Basics of qualitative research: Techniques and procedures for developing grounded theory (2nd ed.). Newbury Park, CA: Sage.

Tsai, E., \& Fung, L. (2005). Perceived constraints to leisure time physical activity participation of students with hearing impairment. Therapeutic Recreational Journal, 39, 192-206.

World Health Organization. (2014). Deafness and hearing loss. Retrieved from http://www.who.int/pbd/deafness/ hearing_impairment_grades/en/index.html 